\title{
SIMULAÇÃO DA SECAGEM PERIÓDICA DE FEIJÃO EM LEITO FIXO
}

\author{
R. O. DEFENDI ${ }^{1}$, R. O. da SILVA ${ }^{1}$, P. R. PARAÍSO ${ }^{1}$ e L. M. de M. JORGE ${ }^{1}$ \\ ${ }^{1}$ Universidade Estadual de Maringá, Departamento de Engenharia Química \\ E-mail para contato: rafael.defendi@hotmail.com / lmmj@deq.uem.br
}

\begin{abstract}
RESUMO - O estudo da secagem periódica de grãos em leito fixo tem apresentado um melhor desempenho em relação à secagem convencional, realizada com as condições de temperatura e de vazão do ar de secagem constantes. A operação periódica consiste na modulação dessas condições de alimentação do ar em certa amplitude e frequência continuamente. Esta operação pode reduzir a demanda energética do processo a fim de se obter teores de umidades adequados para a armazenagem do feijão. Neste contexto, efetuaram-se a modelagem, simulação e análise das duas formas de secagem: convencional e periódica, destacando-se as vantagens e limitações desta nova modalidade de secagem de grãos. As simulações foram realizadas para casos que demandaram o mesmo consumo energético. Dos resultados, observou-se que a secagem periódica apresentou níveis de umidade do grão menores em comparação aos resultados simulados em operação convencional para os mesmos tempos de secagem e consumo energético.
\end{abstract}

\section{INTRODUÇÃO}

Dados da Conab apontam que a produção brasileira de feijão no ano safra 2012/2013 foi em torno de 3 milhões de toneladas. Segundo projeções feitas pelo Ministério da Agricultura Pecuária e Abastecimento, em dez anos está previsto um crescimento na produção de feijão de $14,2 \%$, quantidade suficiente para suprir o consumo médio nacional. Contudo, um dos problemas enfrentados atualmente durante a produção de feijão, como também de qualquer outro grão, está concentrado em seu armazenamento. De acordo com Oliveira e Rocha (2007), a quantidade perdida de grãos brasileiros vindos da lavoura já esteve próxima a $30 \%$.

O armazenamento de grãos é um processo necessário, uma vez que sua produção é periódica e as demandas das indústrias e do comércio são ininterruptas (Puzzi, 2000). Uma colheita realizada em dois meses pode ser consumida durante um ou mais anos. Contudo, muitos fatores podem prejudicar a qualidade destes grãos enquanto eles estão armazenados. De acordo com Puzzi (2000), estes fatores podem ser um agente físico (temperatura, teor de umidade, danos mecânicos) ou um agente biológico (microorganismos, insetos, fungos). Este autor ainda ressalta que é importante controlar e minimizar os efeitos provenientes destes fatores para garantir a qualidade e a composição química (carboidratos, gorduras, proteínas, fibras, minerais e vitaminas) destes grãos.

Observa-se que o teor de umidade é o fator predominante que controla a qualidade do grão 


\section{9 a 22 de outubro de 2014 \\ Florianópolis/SC}

estocado (Puzzi, 2000). Em baixos valores de umidade, as reações enzimáticas são reduzidas como também as taxas de respiração inerentes ao metabolismo do grão que podem levar o material à podridão. O teor de umidade pode ser controlado pelo processo de secagem. Neste contexto, é importante secar grãos colhidos até níveis seguros de umidade para se alcançar um armazenamento ideal sem riscos de deterioração dos grãos (Puzzi, 2000; Martins et al., 2002). O nível seguro de teor de umidade para se armazenar o feijão durante um ano é de $13 \%$ em base úmida e para períodos superiores a um ano é de $12 \%$ em base úmida (Lazzari, 1993).

Muitos produtores brasileiros usam armazéns para estocar grãos e utilizam as condições naturais do ambiente para secar os grãos enquanto estes ainda estão na lavoura (Martins et al., 2002). Embora as condições do clima brasileiro sejam favoráveis, esta prática de secagem natural não tem sido eficiente para evitar perdas tanto quantitativas quanto qualitativas do material armazenado (Martins et al., 2002). Por outro lado, a secagem forçada com ar quente pode garantir as condições ideais de armazenamento, possibilitando que o grão chegue a níveis de umidade satisfatórios para evitar estas perdas. Embora o processo de secagem com ar quente seja muito utilizado pelas indústrias de grãos, este processo encarece os custos de produção devido a grande demanda de energia necessária para movimentar e aquecer o ar de secagem (Biagi et al., 2002). De acordo com Silva et al. (2000), a secagem em temperaturas altas pode consumir $60 \%$ ou mais do total de energia usada na produção de produtos agrícolas.

Neste contexto, este trabalho visa estudar uma alternativa para reduzir estes custos por meio da operação periódica, a qual pode potencializar os transportes de massa e de energia envolvidos no processo proporcionando uma redução no consumo energético. A operação periódica consiste numa contínua modulação das condições operacionais (como a temperatura e a velocidade do ar) numa específica frequência e amplitude. Como as taxas de secagem não são linearmente dependentes da temperatura do ar, a operação periódica pode alcançar uma eficiência maior em comparação a operação convencional (realizada com temperatura e vazão do ar constantes) em processos em que ambas as operações são tomadas com o mesmo gasto energético e tempo de secagem.

O estudo da secagem periódica de grãos é recente e há poucas referências sobre este assunto atualmente. Contudo, alguns autores estudaram a operação periódica em reatores químicos onde observaram que a modulação das condições dos reagentes pode melhorar o rendimento do reator (Silveston e Hanika, 2004; Lange et al., 1999; Rouge et al., 2001; Tukac et al., 2007). De acordo com Silveston e Hanika (2004), a operação periódica em reatores trifásicos pode mudar a seletividade e aumentar tanto a conversão quanto o rendimento. Estes autores ainda acrescentam que as taxas de reação são potencializadas sob a periódica interrupção do fluxo para leitos gotejantes.

Na secagem de grãos, Romero et al. (2010) estudaram a secagem periódica de soja em leito profundo por meio de um modelo heterogêneo a duas fases. Neste estudo, estes autores observaram que a operação periódica pode melhorar o rendimento do secador e também reduzir o consumo energético em comparação à operação convencional.

Neste contexto, o objetivo deste trabalho foi efetuar a modelagem, a simulação e a análise das duas formas de secagem: a convencional e a periódica, destacando-se as vantagens e limitações desta 
nova modalidade na secagem de feijão em leito profundo. As simulações foram realizadas em condições de mesmo gasto energético e mesmo tempo de secagem para ambas as operações por meio de um modelo matemático a duas fases.

\section{METODOLOGIA}

\subsection{Modelo Matemático}

O modelo utilizado para simular a secagem de feijão em leito fixo foi o modelo heterogêneo a duas fazes, o qual considera o ar e o grão como fases distintas, ou seja, há uma temperatura e umidade especifica tanto para o grão quanto para o ar num dado tempo e numa dada posição do leito. Este modelo já foi usado por alguns autores (Coutinho et al., 2009) na secagem em leito profundo de grãos, o qual geralmente é baseado nas seguintes suposições:

O volume da fase sólida é tomado como constante com o tempo; a variação da massa específica do sólido seco e do ar é negligenciada; comportamento ideal para a fase gasosa, que é considerada apenas formada por ar e vapor de água; despreza-se a variação da porosidade do leito; considera-se constante a viscosidade da fase gasosa; o sólido seco e o líquido formam uma única fase homogênea; são constantes as velocidades de ambas as fases; desprezam-se os fluxos radiais difusivos e condutivos, a radiação térmica, a dissipação viscosa, a compressibilidade da fase gasosa e as perdas de calor pelas paredes do sistema (adiabático); negligencia-se o acúmulo da fase fluida no leito, uma vez comparada ao mesmo termo da fase sólida. Em base nessas considerações, o modelo resulta num sistema composto por quatro equações diferenciais:

$$
\begin{aligned}
& \frac{\partial Y g}{\partial z}=\frac{K_{s} a \cdot\left(Y s-Y s_{e}\right)}{G g} \\
& G g \cdot\left(c p_{a r}+Y g \cdot c p_{v}\right) \frac{\partial T g}{\partial z}=-h a(T g-T s) \\
& \frac{\partial Y s}{\partial t}=-\frac{K_{s} a \cdot\left(Y s-Y s_{e}\right)}{(1-\varepsilon) \cdot \rho_{s s}} \\
& (1-\varepsilon) \cdot \rho_{s s} \cdot\left(c p_{s}+Y s \cdot c p_{l}\right) \cdot \frac{\partial T s}{\partial t}=h a(T g-T s)-K_{s} a \cdot\left(Y s-Y s_{e}\right) \cdot\left(c p_{v}(T g-T s)+\lambda\right)
\end{aligned}
$$

Onde Yg é a umidade do gás em base seca, z é a posição axial no leito, $\mathrm{K}_{\mathrm{s}} \mathrm{a}$ é o coeficiente volumétrico de transferência de massa, Ys é a umidade do grão em base seca, Ys $s_{\mathrm{e}}$ é a umidade do sólido de equilíbrio em base seca, Gg é o fluxo mássico de ar, $\mathrm{cp}_{\mathrm{ar}}$ é o calor específico do ar, $\mathrm{cp}_{\mathrm{v}}$ é o calor específico do vapor, Tg é a temperatura do gás, ha é o coeficiente global de transferência de calor entre o sólido e o gás, Ts é a temperatura do sólido, t é o tempo, $\varepsilon$ é a porosidade do leito, $\rho_{\mathrm{ss}}$ é a massa específica do sólido seco, $\mathrm{cp}_{\mathrm{s}}$ é o calor específico do sólido, $\mathrm{cp}_{1}$ é o calor específico do líquido e $\lambda$ é o calor latente de vaporização.

A porosidade do leito e a massa específica do feijão foram tomadas em base nos resultados obtidos por Resende et al. (2008). O calor específico do feijão considerado foi retirado do estudo de 
Mata et al. (1999). O coeficiente global de transferência de calor entre o feijão e o ar de secagem foi calculado pela expressão ajustada por Boyce (1965). As propriedades do ar, do líquido e do vapor foram consideradas em base dados fornecidos por Perry e Green (1998). O coeficiente de transferência de massa foi estimado pela expressão ajustada por Martins et al. (2002 b).

\subsection{Simulação da Operação Periódica e Convencional}

Nas simulações em operação periódica, foi modulada a temperatura do ar na entrada do secador num formato senoidal como apresentado na Figura 1. Para cada simulação em operação periódica, uma simulação em operação convencional foi realizada com a temperatura de entrada do ar mantida constante no valor igual à média da temperatura de entrada do ar da respectiva operação periódica para garantir que ambas as operações fossem simuladas com o mesmo consumo energético referente ao aquecimento do ar. A expressão usada para o cálculo desse consumo energético segue abaixo:

$$
E=G \cdot \int_{0}^{t} c p_{a r} \cdot T \cdot d t
$$

Onde E é o consumo energético, G é a vazão mássica de ar e T é a temperatura do ar na entrada do leito. $\mathrm{O}$ valor da temperatura média da operação periódica, cujo valor equivale a temperatura constante em operação convencional foi calculado pela seguinte equação:

$$
\bar{T}=\frac{\int T \cdot d t}{\int d t}
$$

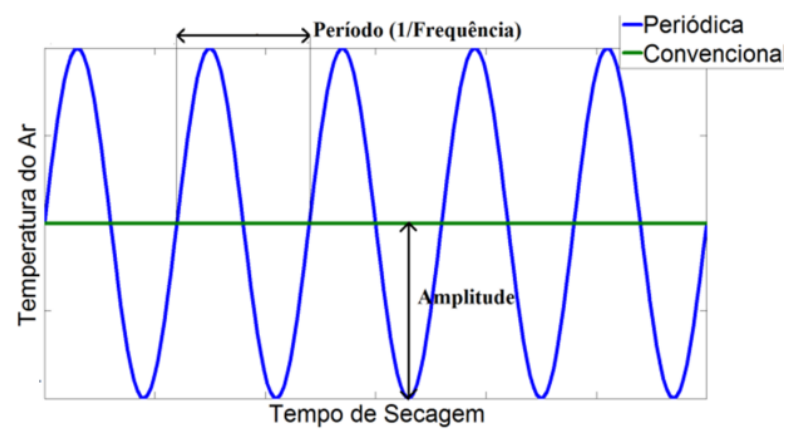

Figura 1 - Modulação da Temperatura do Ar

A equação usada para modular a temperatura do ar em operação periódica foi:

$$
T_{p}=A m p \cdot \operatorname{sen}(\text { fr.t. } 2 \pi)+T_{c}
$$

Onde $\mathrm{T}_{\mathrm{p}}$ é a temperatura de entrada do ar em operação periódica, Amp é a amplitude em ${ }^{\circ} \mathrm{C}$, fr é a frequência em s${ }^{-1}$ e $T_{c}$ é a temperatura de entrada do ar em operação convencional. As simulações foram realizadas para períodos de 6 a 60 minutos e amplitudes de 7 a $20{ }^{\circ} \mathrm{C}$. O tempo de simulação foi igual para ambas as operações. A umidade inicial do feijão foi tomada com o valor de 0,2 em base seca e o ar de secagem foi considerado sem umidade na entrada do leito. 
As simulações foram realizadas em um secador vertical, cilíndrico e isolado com $30 \mathrm{~cm}$ de altura e $6 \mathrm{~cm}$ de diâmetro. O fluxo de ar foi tomado no sentido ascendente com velocidade de 100 $\mathrm{L} / \mathrm{min}$. O modelo foi resolvido pelo método das diferenças finitas para frente, dividindo-se o sistema numa malha com 200 divisões no espaço e 200 divisões no tempo.

\section{RESULTADOS E DISCUSSÕES}

Observou-se que a operação periódica pode ser mais vantajosa do que a operação convencional para simulações nas quais ambas as operações possuem o mesmo gasto energético. Dependendo da frequência e da amplitude da modulação da temperatura do ar na entrada do secador, a operação periódica pode apresentar maiores taxas de secagem. A Figura 2 apresenta o perfil médio de umidade do feijão do leito para as operações periódicas e suas respectivas convencionais para casos de diferentes modulações de temperatura. É possível verificar dessa figura que quanto maior o valor da modulação da temperatura, maiores são as taxas de secagem, pois foi possível se atingir níveis menores de umidade do feijão, favorecendo assim a operação periódica. Quanto maior o valor da amplitude, maiores são os valores dos picos que a temperatura do ar atinge, modificando as taxas de secagem e as condições de equilíbrio e potencializando os transportes de massa e de energia envolvidos no processo. Como as taxas de secagem não são linearmente dependentes da temperatura do ar, esta modulação na temperatura pode aumentar a eficiência do secador em comparação à operação realizada em temperatura constante e com o mesmo gasto energético que a operação periódica.

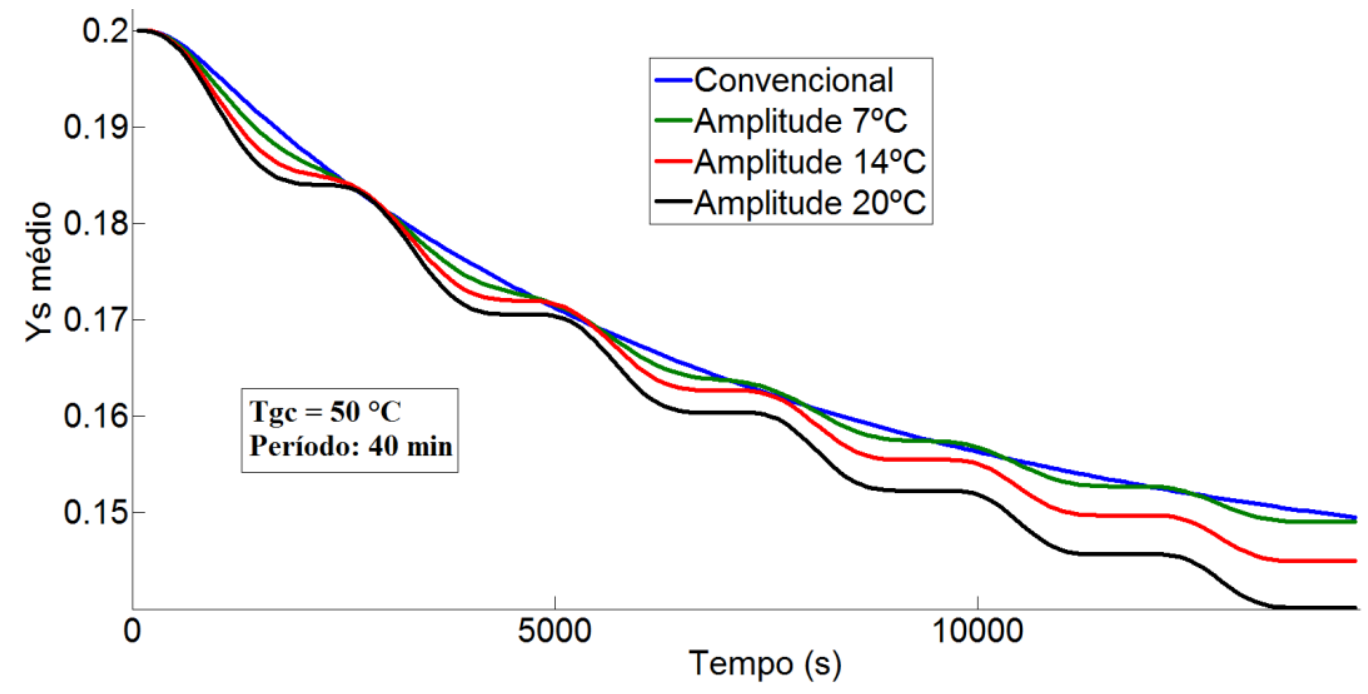

Figura 2 - Teor de Umidade Média do Feijão para Diferentes Amplitudes seguinte:

A equação utilizada para calcular a umidade média do feijão $(\overline{Y S})$ presente no leito foi a

$$
\overline{Y S}=\frac{\int Y s \cdot d z}{\int d z}
$$


A umidade do feijão varia na posição do leito conforme o progresso da secagem. A Figura 3 apresenta o perfil de umidade do grão na entrada e na saída do leito para uma operação periódica e sua respectiva operação convencional. Desta figura é possível verificar que tanto no topo quanto na entrada do leito os níveis de umidade do grão são menores na operação periódica em comparação a sua operação convencional realizado com mesmo gasto energético. Este resultado indica que em operação periódica o rendimento do secador foi maior, pois a quantidade de água evaporada foi maior. Além disso, é possível observar que a variação de umidade no leito é maior na operação periódica, pois a diferença de umidade entre o topo e a entrada do leito é maior no final da secagem. Apesar de a operação convencional atingir mais rapidamente um perfil homogêneo de umidade, esta leva mais tempo para atingir certo valor de umidade em comparação a operação periódica, onde as taxas de secagem foram maiores.

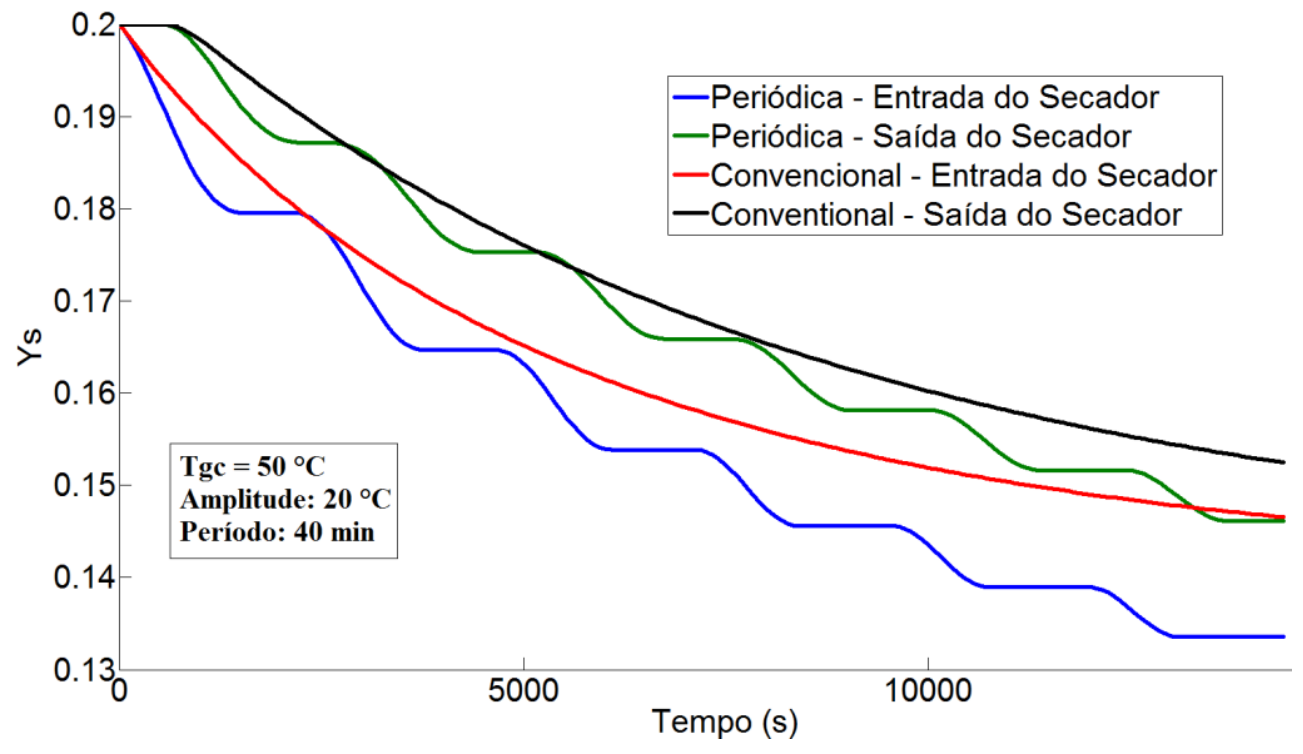

Figura 3 - Perfil de Umidade do Feijão na Entrada e na Saída do Leito

Outro fato interessante a ser ressaltado foi que pequenas amplitudes nas oscilações da temperatura não foram ideais para favorecer a operação periódica uma vez que os perfis de umidade do feijão ficaram muito próximos aos perfis em operação convencional como apresenta a Figura 2 na amplitude de $7{ }^{\circ} \mathrm{C}$. Este comportamento foi análogo a modulação do período das oscilações como apresenta a Figura 4, a qual apresenta os perfis médios de umidade de feijão para diferentes períodos de modulação da temperatura de entrada do ar. Desta figura, é possível observar que para o período de 6 minutos, os níveis de umidade de feijão da operação periódica e da convencional foram muito próximos. Por outro lado, nas oscilações com períodos de 24 e 60 minutos, mesmo que o valor da amplitude de oscilação da temperatura é o mesmo que o valor do período de 6 minutos, os resultados apontaram que as taxas de secagem foram maiores, levando o feijão a níveis menores de umidade. 


\section{9 a 22 de outubro de 2014 \\ Florianópolis/SC}

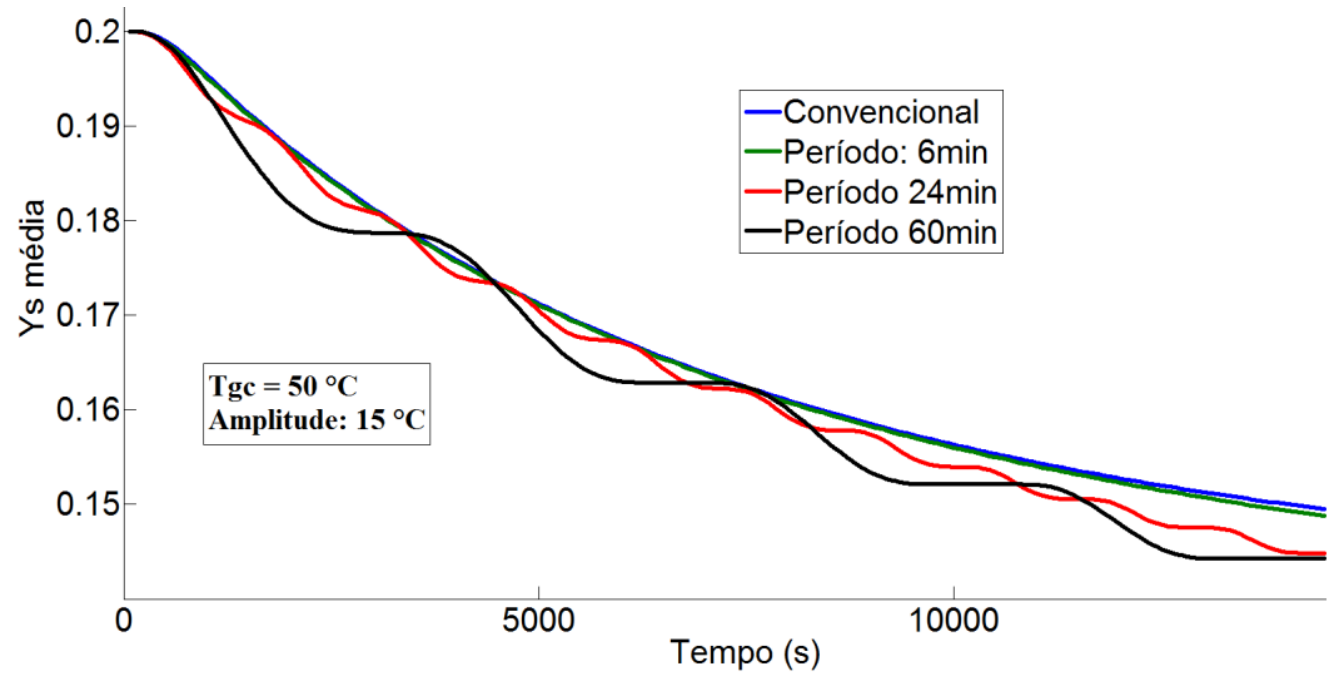

Figura 4 - Teor de Umidade Média do Feijão para Diferentes Períodos

\section{CONCLUSÃO}

Das simulações realizadas, observou-se que a operação com modulação da temperatura do ar na entrada do secador pode ser mais vantajosa, potencializando os transportes de massa e de energia em comparação à operação convencional em casos em que ambas as operações demandam o mesmo gasto energético. Observou-se que quanto maior a amplitude de modulação da temperatura do ar, maiores são as taxas de secagem levando a umidade do leito a níveis menores de umidade. Por outro lado observou-se que quanto maior esta amplitude, maiores são os gradientes de umidade dentro do leito retardando o tempo no qual o leito atinge um perfil homogêneo. Além disso, verificou-se que baixos valores de período e de amplitude da modulação do ar não favorecem a operação periódica, uma vez que as taxas de secagem foram próximas às obtidas em operação convencional.

\section{AGRADECIMENTOS}

O presente trabalho foi realizado com o apoio do Conselho Nacional de Desenvolvimento Científico e Tecnológico - CNPq - e com o apoio da Coordenação de Aperfeiçoamento de Pessoal de Nível Superior - CAPES - Brasil.

\section{REFERÊNCIAS}

BIAGI, J. D.; BERTOL, R.; CARNEIRO, M. C. Secagem de grãos para unidades centrais de armazenamento. In Armazenagem de Grãos. LORINI, I.; MIIKE, L. H.; SCUSSEL, V. M.; Campinas: Instituto Bio Geneziz, 2002; 289-307.

BOYCE, D. S. Grain Moisture and Temperature Changes with Position and Time During Through Drying. J. Agric. Res., v. 10 (4), p. 333-341, 1965.

COUTINHO, M. R.; ROMERO, J. A. S.; CONCEIÇÃO, W. A. S.; PARAÍSO, P. R.; JORGE, L. M. 
M. Secagem de Soja em Leito Fixo: Modelo a Duas Fases. XXXIV Congresso Brasileiro de Sistemas Particulados, ENEMP, 2009.

LANGE, R.; GUTSCHE, R.; HANIKA, J. Forced Periodic Operation of a Trickle-Bed Reactor. Chemical Engineering Science, v. 54, p. 2569-2573, 1999.

LAZZARI, F. A. Umidade, fungos e micotoxinas na qualidade de sementes, grãos e rações. Curitiba: Ed. Do Autor, 1993.

MARTINS, R. M.; FRANCO, J. B. da R.; OLIVEIRA, A. V.; ANGONESE, C. Armazéns para propriedade familiar. In Armazenagem de Grãos. LORINI, I.; MIIKE, L. H.; SCUSSEL, V. M.; Campinas: Instituto Bio Genezizs, 2002 a; 117-155.

MARTINS, M. G.; MANCINI, M. C.; BISCAIA JUNIOR, E. C.; Cinética de Secagem de Feijão em Camada Delgada. Revista Universidade Rural, Séria Ciências Exatas e da Terra, v. 21 (1), p. 83-88, 2002 b.

MATA, M. E. R. M. C.; DANTAS, L. A.; BRAGA, M. E. D.; Programa Computacional Para Simulação de Secagem de Grãos. Revista Brasileira de Produtos Agroindustriais, v. 1 (1), p. 33-50, 1999.

OLIVEIRA, C. A.; ROCHA, S. C. S. Intermittent Drying of Beans In a Spouted Bed. Brazilian Journal of Chemical Engineering, v. 24 (4), p. 571-585, 2007.

PERRY, R. H.; GREEN, D. W. Chemical Engineer's Handbook. Estados Unidos: McGraw-Hill, 1998.

PUZZI, D. Abastecimento e Armazenagem de Grãos. Campinas: Instituto Campineiro de Ensino Agrícola, 2000.

RESENDE, O.; CORRÊA, P. C.; GONELI, A. L. D.; RIBEIRO, D. M. Propriedades Físicas do Feijão Durante a Secagem: Determinação e Modelagem. Ciênc. Agrotec., v. 32 (1), p. 225-230, 2008.

ROMERO, J. A. da S.; OMOTO, E. S.; CONCEIÇÃO, W. A. dos S.; COUTINHO, M. R.; PARAÍSO, P. R.; JORGE, L. M. M. Estudo da secagem de soja em operação periódica. COBEQ XVIII Congresso Brasileiro de Engenharia Química, Foz do Iguaçú, Brasil, Setembro, 2010.

ROUGE, A.; SPOETZL, B.; GEBAUER, K.; SCHENK, R.; RENKEN, A. Microchannel reactors for fast periodic operation: the catalytic dehydration of isopropanol. Chemical Engineering Science, v. 56, p. 1419-1427, 2001.

SILVA, J. S.; AFONSO, A. D. L.; DONZELLES, S. M. L. Secagem e Secadores. In Secagem e Armazenagem de Produtos Agrícolas. SILVA, J. S. Viçosa: Aprenda Fácil, 2000; 107-138.

SILVESTON, P. L.; HANIKA, J. Periodic Operation of Three-Phase Catalytic Reactors. The Canadian Journal of Chemical Engineering, v. 82, p. 1105-1142, 2004.

TUKAC, V.; SIMICKOVÁ, M.; CHYBA, V.; LEDERER, J.; KOLENA, J.; HANIKA, J.; JIRICNY, V.; STANEK, V.; STAVÁREK, P. The behavior of pilot trickle-bed reactor under periodic operation. Chemical Engineering Science, v. 62, p. 4891-4895, 2007. 